\title{
Os quadrinhos silenciosos contra a memória de silenciamento dos queer: identidade e sexualidade em Quadrinhos Queer
}

\section{The silent comics against the queer silencing memory: identity and sexuality in Quadrinhos Queer}

Guilherme Sfredo Miorando ${ }^{1}$ 


\section{Resumo}

Este artigo propõe explorar a relação entre o silenciamento da população queer na vida pública e a expressão do silêncio nas narrativas gráficas. Para tanto procurou-se entender, a partir de Eni Puccinelli Orlandi, como o silêncio opera sobre as narrativas em quadrinhos a ponto de engendrar uma supressão nas palavras, mas falar tão detalhadamente através de imagens, como atesta Thierry Groensteen. Buscou-se entender que violências simbólicas passam a repercutir na memória das pessoas queer, para desenvolverem esse tipo de comunicação, pensando nas vidas precárias de Judith Butler. Também, em consonância com o pensamento de David Lapoujade, procurou-se entender quais os papéis da mídia, da arte e da memória na criação de narrativas em que os gestos e não as palavras são os fios condutores da experiência que se interpõe entre a obra e o artista.

Palavras-chave

Histórias em quadrinhos, memória, queer, silêncio, silenciamento.

\section{Abstract}

This article proposes to explore the relationship between the silencing of the queer population in public life and the expression of silence in graphic narratives. To this end, we sought to understand, starting with Eni Puccinelli Orlandi, how silence operates on comic narratives to the point of engendering a suppression in words, but speaking in such detail through images, as attested by Thierry Groensteen. We tried to understand that symbolic violence starts to reverberate in the queer people's memory, to develop this type of communication, thinking about Judith Butler's precarious lives. Also, in line with the thinking of David Lapoujade, to understand what are the roles of the media, art and memory in the creation of narratives in which gestures and not words are the guiding threads of the experience that interposes between the work and the artist.

\section{Keywords}

Comics, memory, queer, silence, silencing. 


\section{Quadrinhos Queer}

O livro Quadrinhos Queer é uma antologia publicada em 2021 pela Skript Editora que revela diferentes produções dos quadrinistas queer brasileiros. Através da palavra queer, os organizadores da publicação quiseram abarcar minorias sexuais formadas atualmente pelo acrônimo LGBTQIA+, em consonância com a ideia de Judith Butler (2018, p. 79) de que "o termo queer não designa identidade, mas aliança". Um fator que chama atenção nas histórias em quadrinhos reunidas e publicadas na obra é o número expressivo de contribuições no formato de "quadrinhos silenciosos". Esse tipo de produção também é conhecido como quadrinhos mudos, quadrinhos sem palavras ou sem diálogos. Trata-se de uma forma de narrativa que usa quadros em "solidariedade icônica" (GROENSTEEN, 2015), para criar um sentido temporal e espacial que desenvolve uma história apenas com imagens, ou seja, sem palavras.

A coletânea Quadrinhos Queer é um modo de dar visibilidade e representatividade ao trabalho artístico de pessoas queer, uma vez que os indivíduos enquadrados nesse grupo têm sido alvo de campanhas de ódio em tempos recentes. Alguns exemplos destas cruzadas nos últimos anos vão da perseguição à filósofa Judith Butler em sua vinda ao Brasil, em 2017, às fake news sobre a distribuição de um "Kit Gay" nas escolas públicas, entre 2004 e 2011, bem como o fechamento da exposição "Queermuseum" em Porto Alegre, também em 2017. Na seara das histórias em quadrinhos, o caso mais notório foi a perseguição do então prefeito do Rio de Janeiro, Marcelo Crivella, à graphic novel Vingadores: a cruzada das crianças, durante a Bienal do Livro na cidade, no ano de 2019. Acontecimentos como esses denotam uma espécie de repressão às pessoas que vivem à margem da sexualidade normatizada, que podem ser descritas como "vidas precárias" pelo pensamento de Judith Butler (2019) e como "existências mínimas" conforme David Lapoujade (2017).

Este artigo propõe explorar a relação entre o silenciamento da população queer na vida pública e a expressão do silêncio nas narrativas gráficas. Para tanto, procura-se entender como o silêncio opera sobre as narrativas em quadrinhos a 
ponto de engendrar uma supressão nas palavras, mas falar tão detalhadamente através de imagens. Busca-se entender que violências simbólicas passam a repercutir na memória das pessoas queer, para desenvolverem esse tipo de comunicação, bem como compreender quais os papéis da mídia, da arte e da memória na criação de narrativas em que os gestos e não as palavras são os fios condutores da experiência que se interpõe entre a obra e o artista.

\section{Nomeando o silêncio}

Em As formas do silêncio, de Eni Puccinelli Orlandi (2007), uma das obras em português fundamentais para entendermos o "discurso do silêncio", a autora expõe que, para compreendermos a linguagem, o silêncio é essencial, pois são nesses momentos em que elaboramos os sentidos das linguagens às quais somos submetidos. Para Orlandi, o silêncio é fundante, e a linguagem "é a conjunção significante da existência e é produzida pelo homem para domesticar a significação" (ORLANDI, 2007, p. 32). Coloca ainda que "O silêncio fundamenta o movimento de interpretação. Ele é o ponto de apoio do giro interpretativo" (2007, p. 156). Se observarmos o silêncio dentro da linguagem dos quadrinhos, a autora nos apresenta algumas pistas que podemos trazer para nossa análise.

Orlandi acredita que para tornar o silêncio visível precisamos observá-lo através de métodos discursivos históricos, críticos e desconstrutivistas. Neste artigo, optamos por vislumbrá-lo através do olhar queer, que envolve essas três instâncias. Ainda assim, segundo a autora, dentro das instâncias do silêncio só podemos encontrar pistas e traços, e não marcas formais.

A autora acredita que todo processo de significação tem uma relação necessária com o silêncio. Este seria o primeiro tipo de silêncio: o silêncio fundante, a partir do qual a linguagem brota. O segundo tipo seria a política do silêncio (o silenciamento), denota que o sentido sempre é produzido a partir de um espaço, de um lugar e de um sujeito, ou seja, o sentido é contextual. Quando o sujeito diz alguma coisa, ele estará "necessariamente, não dizendo 'outros' sentidos. 
Isso produz um recorte necessário no sentido. Dizer e silenciar andam juntos. Ou seja, o silêncio recorta o dizer" (ORLANDI, 2007, p. 53).

Com efeito, a política do silêncio se define pelo fato de que ao dizer algo apagamos necessariamente outros sentidos possíveis, mas indesejáveis, em uma situação discursiva dada. A diferença entre o silêncio fundador e a política do silêncio produz um recorte entre o que se diz e o que não diz, enquanto o silêncio fundador não estabelece nenhuma divisão: ele significa por (em) si mesmo. (ORLANDI, 2007, p. 73)

Por muito tempo, as pessoas queer foram silenciadas. Os discursos, sentidos e contextos que regiam a sociedade vinham das camadas legitimadas desta, das quais as pessoas queer não faziam parte e por isso muitos dos seus direitos de expressão eram negados, silenciosamente, através de uma política do silêncio. Segundo Orlandi, "a censura afeta, de imediato, a identidade do sujeito" (2007, p. 79). Quando não se fala das pessoas queer e de suas questões, significa que elas, em teoria, não existem. Dentro dos trabalhos de Judith Butler, como em Excitable speech (1997), a força da linguagem e dos sentidos que os nomes, principalmente os xingamentos evocam, são parte fundamental para a construção da identidade. Orlandi, em sua análise do silêncio, acredita que este "intervém como parte da relação dos sujeitos com o dizível, permitindo os múltiplos sentidos ao tornar possível, ao sujeito, a elaboração de sua relação com outros sentidos" (2007, p. 89). É essa uma das funções do silêncio fundante, que distancia o indivíduo do silenciamento, criado por meio dos contextos sociais em que está inserido. O silêncio fundante, dessa forma, rompe com o consenso do silenciamento, permitindo com que o sujeito desenvolva e construa sua identidade através de sua própria relação com os sentidos que experimenta ao longo de sua existência. Nas palavras de Orlandi (2007, p. 90):

O silêncio trabalha as diferenças inscritas nos processos de identificação do sujeito, produzindo seu sentimento de unidade, integrando diversos aspectos de um sujeito que "diz". A identidade, no entanto, não se reduz à identificação; ela mobiliza processos mais complexos. Um desses processos nos permite apreciar a produção da diferença, justamente pela forma como 
o silêncio faz parte da relação do sujeito com o sentido. Diríamos mesmo que a diferença, na identidade, torna-se possível através do silêncio.

Para a autora, o silêncio gera uma errância, uma "migração de sentidos", que afeta tanto a produção da identidade e da diferença, como a circulação de sentidos em que surge a memória, pois, segundo ela, "a matéria significante tem memória", levando a crer que existe uma historicidade na linguagem. Essa matéria de história e memória coletiva faz com que determinados sentidos sirvam para toda uma sociedade, mas isso não quer dizer que essa mesma sociedade esteja imune à contradição entre o novo e o mesmo, entre o outro e o sentido comum. Orlandi expõe que o dizer de uma memória é "o saber dos sentidos". Através dessa tradição de significados, uma realidade se sistematiza e toma forma. É por meio da memória que o sentido se torna visível pela instituição e pelo consenso social.

Pensando historicamente, as pessoas queer vêm sofrendo uma política do silêncio e um silenciamento sobre suas vidas. Elas só eram destaque na memória coletiva brasileira, por exemplo, como alvo de chacota e aviltamento. Não se devia falar dessas pessoas e elas não poderiam se expressar para dar sua visão sobre suas existências. Tornando-se, então, vidas precárias e existências mínimas como veremos na próxima seção deste artigo.

\section{Vidas precárias e existências mínimas}

Diversos sites e veículos de notícias apresentam ano a ano o aumento da violência contra pessoas queer no Brasil². O país lidera as estatísticas mundiais de assassinatos de pessoas queer, sendo uma morta por dia em crimes influenciados por discriminação sexual. Contudo, muitas vezes, esse tipo de crime é subnotificado, em parte por fragilidades do Estado brasileiro, em parte pelas questões identitárias das pessoas queer que sofrem assassinatos. A falta de maior detalhamento e de maior interesse sobre os crimes cometidos contra pessoas queer podem estar conectados com o silenciamento sofrido por essa minoria, revelando também 
a homotransfobia presente em diversos aspectos da cultura brasileira, fazendo com que as pessoas queer acabem enquadradas como irreais (BUTLER, 2019) ou virtuais (LAPOUJADE, 2017), ou ainda como deixadas fora do quadro. Assim, se essa violência é cometida contra pessoas irreais, "não há violação nenhuma ou negação dessas vidas, uma vez que elas já foram negadas" (BUTLER, 2019, p. 54). Já estão em "estado de morte", em silêncio, impedidas de se manifestar. Se persistem e tentam se colocar como vivas, devem ser assassinadas para confirmar seu estado de silenciamento e de morte.

Para Lapoujade (2017), tornar "mais" reais este tipo de existência, legitimálas e dar a elas o direito de existir depende de um fundamento. Esse fundamento poderia ser encontrado nas artes, como por exemplo, no nosso caso, a coletânea Quadrinhos Queer, que segundo o autor seria uma intensificadora da realidade. Esse fator consolida as existências mínimas, em que os virtuais passam a existir para aqueles que fruem de seus trabalhos ou de uma representação de sua vida. Para o pensador, "são os virtuais que introduzem um desejo de criação, uma vontade de arte no mundo. Eles são a origem de todas as artes que praticamos" (LAPOUJADE, 2017, p. 38). Butler (2019, p. 66) complementa esse pensamento na seguinte citação:

\footnotetext{
Pedir por reconhecimento, ou oferecê-lo, é precisamente não pedir reconhecimento pelo que já somos. É solicitar um devir, uma transformação, fazer um apelo ao futuro sempre em relação ao Outro. É também apontar a própria existência de si, e a própria persistência na existência de si, na luta pelo reconhecimento.
}

Além disso, para Lapoujade "criar é antes de tudo testemunhar" (2017, p. 93), e aqui encontramos a força da necessidade da memória ser tornada arte e mídia para reforçar a existência das vidas precárias. Segundo Michael Pollack (1989, p. 6) "para poder relatar seus sofrimentos, uma pessoa precisa antes de mais nada encontrar uma escuta", entende-se assim que a existência de uma mídia que comporte diversas realidades queer concretiza-se não só como uma escuta, mas uma figura legitimadora e de receptáculo dessas existências em forma de arte, em forma de arquivo. 
Para Ann Cvetkovich (2008), os arquivos são evidências efêmeras da vida queer e muitas vezes não conseguem separar a fronteira entre público e privado. Desse modo, leva-se a crer que mesmo os quadrinhos queer que são mais fantasiosos guardam boa parte de elementos autobiográficos. Isso também se confirmaria, segundo Valerie Rohy (2010), que se acredita existir uma obsessão queer pelo arquivamento, já que sua memória coletiva, sua história e sua existência são alijadas da continuidade oficial. Assim o arquivo serviria não para os olhos dos outros mas como uma espécie de ferramenta de autodefinição. No caso da antologia Quadrinhos Queer, a criação, a memória e a experiência dos outros se encontram nas páginas das histórias em quadrinhos selecionadas e desenvolvidas para a posteridade. Os quadrinhos silenciosos, portanto, seriam formas de abordar os elementos autobiográficos através daquilo que Michael Pollack chama de "não-ditos":

Essas lembranças proibidas, indizíveis ou vergonhosas são zelosamente guardadas em estruturas de comunicação informais e passam despercebidas pela sociedade englobante. Por conseguinte, existem nas lembranças de uns e de outros zonas de sombra, silêncios, "não-ditos". As fronteiras desses silêncios e "não-ditos" com o esquecimento definitivo e o reprimido inconsciente não são evidentemente estanques e estão em perpétuo deslocamento. Essa tipologia de discursos, de silêncios, e também de alusões e metáforas, é moldada pela angústia de não encontrar uma escuta, de ser punido por aquilo que se diz, ou, ao menos, de se expor a mal-entendidos. (POLLACK, 1989, p. 8)

Pollack também coloca que existe uma frequente interação entre o vivido e o aprendido e entre o vivido e transmitido, e é isso que causa aquilo que ele chamou de "memória subterrânea das sociedades", em que determinados grupos são levados em consideração em detrimento de outros. De acordo com o autor, uma solução para o silenciamento de determinados grupos é observar contextos a favor ou contra memórias marginalizadas para entender como aquelas lembranças do passado são afetadas pelo momento presente. 


\section{Memória x silenciamento}

Ressignificar e reimaginar são aspectos dos fenômenos da memória, como atestam grandes pensadores do tema, por exemplo, Maurice Halbwachs (1999) e Joël Candau (2001). É a memória que trabalha e repara os traumas, como a perda de um ente querido e a perda da identidade provocada pelas rupturas que a não aceitação social da condição queer pode acarretar. Em um artigo anterior, verificamos que

os espaços que o quadrinho abarca a partir da memória envolvem o pessoal, o subjetivo, a alteridade e o coletivo, fundidos em um entrelugar que não pode ser facilmente definido com fronteiras estanques, mas permeáveis e rizomáticas como a própria memória. (MIORANDO, 2019, p. 50)

Em uma aproximação com os quadrinhos, Ahmed e Crucifix (2018) apontam duas formas de se estudar a memória nas histórias em quadrinhos: através do estilo ou do arquivo. Dessa forma, "se os estilos modulam o ritmo de recepção de uma história em quadrinhos, os arquivos irão determinar o impacto destas narrativas como merecedoras de uma memória ou não, quando conseguem tocar emocionalmente as pessoas que os consomem enquanto objetos de fãs" (MIORANDO, 2019, p. 50).

Assim, se a memória funciona através do binômio lembrar/esquecer, os quadrinhos funcionam através da dupla mostrar/omitir, que entra em consonância com as práticas mnemônicas apresentadas neste artigo, bem como naquelas práticas que performam os elementos de uma memória cultural coletiva. (MIORANDO, 2019, p. 51)

Mostrar e omitir nos quadrinhos silenciosos trabalha através da visualização da imagem em detrimento da palavra escrita. Contudo, dentro da dinâmica do sistema dos quadrinhos ainda existem as possibilidades de que a justaposição dessas imagens, rodeadas pela sarjeta, pode desenvolver novas significações. A sarjeta é o espaço em branco entre duas ou mais imagens geralmente constritas por um requadro. É ali que o trabalho de sentido dos quadrinhos é realizado, pois une o tempo e o espaço de duas imagens em uma narrativa. A sarjeta tem o mesmo 
serviço para os quadrinhos como a elipse tem para a literatura ou o raccord tem para o cinema. A elipse, enquanto imagem e figura de linguagem, portanto, é do domínio do silêncio. Ao mesmo tempo em que a elipse quebra a linearidade, ela a estabelece, há uma assimetria que garante o trabalho dos sentidos.

Eni Orlandi (2007, p. 23) acredita que "o silêncio é a garantia do movimento dos sentidos", de forma que os quadrinhos silenciosos despertam no leitor mais elucubrações do que os com palavras escritas em balões. "Ao invés de pensar o silêncio como falta, podemos pensar a linguagem como excesso" (ORLANDI, 2007, p. 31). Para a autora, a linguagem é desenvolvida pelo homem para domesticar a significação.

As histórias em quadrinhos são um sistema que se utiliza da linguagem (escrita ou pictórica) dentro de um suporte midiático (analógico ou digital); mais do que domesticar uma significação, traduz uma narrativa através de escolhas deliberadas dos seus autores. Da mesma forma, a nossa memória é adestrada: ela compõe uma linearidade, ou seja, uma narratividade, por meio de fragmentos do passado que são ressignificados no presente.

No caso dos quadrinhos silenciosos, compostos apenas de imagens e signos pictóricos, a memória alcança patamares obscuros e enigmáticos, mas não menos poderosos que a linguagem textual. "Ao contrário dos textos, imagens são mudas e sobredeterminadas; elas podem fechar-se em si ou ser mais eloquentes que qualquer texto", aponta Aleida Assmann (2011, p. 237), completando que a forma como encaramos a memória está vinculada à tecnologia da mídia. "Assim como a escrita, também a imagem é, a um só tempo, metáfora e medium da memória" (2011, p. 237). Enquanto na comunicação entende-se que mídia é um canal pelo qual a mensagem se faz presente, Judith Butler (2018, p. 114) expõe uma outra acepção deste termo:

O termo "mídia" nomeia qualquer forma de apresentação que nos mostre a realidade vista de fora; ela opera por meio de uma série de embargos que podemos chamar de sua mensagem, que nos afeta, com o que eu quero me referir tanto ao embargo - o que é editado, o que fica fora das margens - quanto o que é apresentado. 
Aquilo que Butler nomeia como embargo, podemos muito bem chamar de silenciamento. Entende-se assim que existe uma negociação midiática sobre as vidas que devem ser representadas ou não; da mesma forma como negociamos a nossa identidade e produzimos as nossas memórias, existe um filtro, uma seleção. Em outras palavras, a memória, a identidade e a mídia geram uma sensação de completude para aquilo que é feito de pedaços, de fios rizomáticos e que é editado, seja por meios eletrônicos ou através de nosso cérebro, para dar sentido à nossa existência.

É através dos processos midiáticos, na circulação e recepção de uma história em quadrinhos que a memória se torna arte e, posteriormente, a arte se torna memória. É por meio do ato de se fazer ver em uma história em quadrinhos que o autor irá passar as experiências de como é ser uma pessoa queer, seja através de testemunho ou de ficção, seja através de uma memória autobiográfica. Por outro lado, ao se fazer ver, irá criar um elo mnemônico com o fruidor da história em quadrinhos, que, através da narrativa, se coloca no lugar de um outro que talvez até pouco tempo ignorava ou negava a existência. Colocar as vidas precárias e as existências mínimas em evidência através da arte e da mídia é pedir para que essas pessoas sejam lembradas, sejam consideradas. Dessa forma, vamos tentar, a seguir, entender como o silêncio é trabalhado dentro das histórias em quadrinhos, consideradas uma arte, uma mídia, mas principalmente um sistema de linguagem.

\section{Silêncio nos quadrinhos}

Entre alguns dos quadrinhos silenciosos mais conhecidos do mundo estão as aventuras em mangá do bebê dinossauro Gon (1991-2002), de Masashi Tanaka; o quadrinho norte-americano O sistema (1997), de Peter Kuper, desenhista de Spy vs. Spy, da revista MAD e A chegada (2006), de Shaun Tan, que mistura linguagem dos quadrinhos com a de livros ilustrados e de fotografias. Entre os autores brasileiros, quem mais se destaca atualmente através desse recurso narrativo é Gustavo Duarte, criador de Monstros!, Có!, Taxi e Birds (2009-2014). Para Groesteen (2012, p. 156), os "quadrinhos silenciosos": 
são caracterizados primeiramente por uma sequencialidade muito detalhada, uma análise altamente crítica. Eles têm em comum a eliminação da decoração ou sua redução a sua expressão mais gritante, a fim de se concentrar nos personagens. Esse foco nos atores da história, que são seguidos passo a passo, implica uma terceira característica: um alto nível de redundância.

Ciro Inácio Marcondes (2016) acredita que a linguagem "muda" dos quadrinhos estaria relacionada à aurora da cultura e da cognição humana, e que aqui poderia ser remetida às pinturas rupestres das cavernas de Lascaux, na França, que também são tidas como proto-histórias em quadrinhos por diversos estudiosos. Entretanto, para ele, a origem moderna do que se tem como histórias em quadrinhos estaria dividida entre a utilização das palavras, seja como legendas ou balões, e a sequencialidade pictórica, que contém narratividade. O autor afirma que, para alguns estudiosos da área, se acredita que a definição da mídia histórias em quadrinhos estaria na justaposição de palavras em imagens, mas é certo que a presença ainda hoje de quadrinhos silenciosos põe em xeque esses conceitos.

Dentro de uma história em quadrinhos, "uma imagem é interpretável no sentido em que, dentro de uma narração sequencial como a da história em quadrinhos, ela está sempre próxima de outras imagens, situadas antes ou depois na trajetória narrativa" (GROENSTEEN, 2015, p. 134). Groensteen acredita que apesar de muitos quadrinhos serem de fácil interpretação e que se pode depreender apenas um sentido, muitos deles, sejam silenciosos - sem texto - ou verbais com texto -, podem gerar uma polissemia, ou seja, múltiplos significados.

"Nos quadrinhos contemporâneos, em contraste, há uma corrente inovadora caracterizada por uma poética de reticência, ambigüidade e indeterminação. Alguns autores preferem se desviar do caminho estreito da 'narrativa e nada mais'" (GROENSTEEN, 2013, p. 30). Os artistas que costumam trabalhar com os quadrinhos silenciosos são atraídos por áreas cinzas; imagens que são cortadas à deriva; estratégias de interferência de mensagens de todos os tipos; e, em geral, eles criam conexões entre os painéis que são estruturados por meio da harmonia, ressonância, correspondência, evitando relações que são 
imediatamente decodificáveis em termos de lógica da narrativa e significado. Assim são caracterizados os quadrinhos silenciosos, que se utilizam apenas do recurso das imagens.

\section{Metodologia e forma de análise}

Não é simples fazer uma separação, dentro da mídia dos quadrinhos, do conteúdo que é incorporado pelo leitor de modo a confirmar sua bagagem cultural - vindo de processos da memória coletiva ou de consenso social, por exemplo, nas representações muitas vezes estereotipadas de personagens das histórias em quadrinhos - e daquilo que é absorvido da forma que o autor propõe ao manipular a linguagem do próprio sistema dos quadrinhos. Existe uma partilha de sentidos entre a mecânica da leitura dos quadrinhos e a representação icônica deles. Em quadrinhos com palavras, a definição desses sentidos é mais fechada, enquanto em quadrinhos silenciosos, por se apoiarem apenas em imagens, o significado é mais aberto a interpretações. Nos quadrinhos silenciosos, não apenas o enredo das histórias fica mais difuso, como o desfecho delas também se põe em movimento, podendo gerar diversas interpretações posteriores.

Portanto, para responder às perguntas: "Como o silêncio fundante rompe o silenciamento em Quadrinhos Queer?" e "Quais as implicações desse rompimento para a construção da identidade queer através dos quadrinhos?", utilizamos uma metodologia para identificar visualmente de que forma as pessoas queer são codificadas neste trabalho e que tipo de final os quadrinistas apresentam para suas narrativas.

Neste trabalho, encontramos diferenciações e convergências nos âmbitos cultural (sujeitas a interpretações diversas) e linguístico (inerente a própria dinâmica de leitura de uma história em quadrinhos). A partir dessas definições, podemos entender as implicações da revelação da identidade queer nos quadrinhos de uma forma sutil, porém poderosa, que é o silêncio. Observar o tipo de final que os autores pensaram para suas histórias também nos ajuda a entender o modo de ver desses autores para entender como eles rompem (ou não) com o senso comum e a memória coletiva de o que é ser uma pessoa queer. 
Para desenvolver essa discussão utilizamos a análise pictórica que focaliza a importância das imagens no processo analítico. "Tais imagens ganham importância e relevância dependendo da função da imagem no universo ficcional" (VIANA, 2018, p. 40). Tal importância, dentro de nossa análise, é a revelação de que aquela história que estamos lendo é uma narrativa queer, feita por pessoas queer, com representações dessa identidade. Dentro da análise pictórica, buscamos, a partir do que já foi descrito anteriormente neste artigo, um modo de ver crítico:

O modo de ver crítico é aquele que apresenta uma reflexão totalizante sobre a imagem e sobre o próprio observador, entendendo não apenas a imagem em sua totalidade e historicidade, mas também o observador que está submetido ao mesmo processo de determinações sociais. (VIANA, 2018, p. 47)

Nesse modo de análise, rompe-se com o senso comum e a espontaneidade, dando contornos especializados à interpretação, mas indo além, buscando uma visão totalizante da imagem.

\section{Análise das histórias em quadrinhos silenciosas de Quadrinhos Queer}

Para ilustrar a forma como as identidades queer são trabalhadas na narrativa silenciosa dos quadrinhos, utilizamos como exemplo as oito histórias silenciosas de Quadrinhos Queer. O quadrinho que abre a coletânea é de Flávia Borges, que mostra o acolhimento de uma menina sob o guarda-chuva da outra. Após uma troca de gestos, as duas finalmente dão as mãos sob o guarda-chuva enquanto a tempestade continua a fustigá-las. Podemos interpretar que a forma como as meninas dão as mãos revela não apenas sua sexualidade, como também uma forma de romper o silenciamento, representado pela chuva. O guarda-chuva seria, então, um símbolo da aliança, sob o qual se pode defender da tempestade que as silencia e as impede de expressar os seus sentimentos e a sua sexualidade. Esse significado só pode ser atingido no contexto da produção da coletânea, feita apenas por pessoas queer e de uma forma de interpretação cultural. 


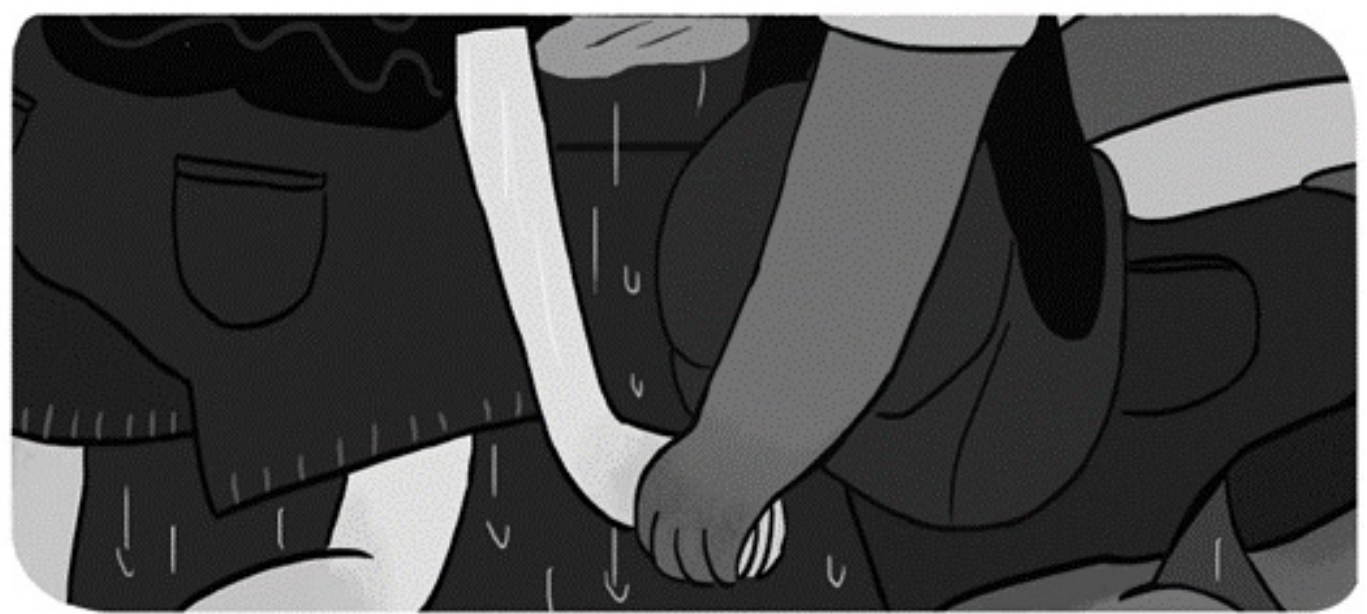

Figura 1: Excerto do quadrinho "Maré Alta", de Flávia Borges Fonte: Borges, Irineu, Smee (2021, p. 21).

Alice Pereira traz uma história em quadrinhos em que acompanhamos um cavaleiro em sua busca para libertar uma princesa. Contudo, quando os dois se veem frente a frente, percebem que princesa e cavaleiro são a mesma pessoa. Neste quadrinho, é a justaposição de imagens entre a representação do cavaleiro e a da princesa que coloca o silêncio fundador como forma de reflexão do significado gerado no espaço entre as duas imagens, a sarjeta. Através dessa elipse, entendemos que o cavaleiro estava procurando a princesa dentro de si, que no fundo, os dois eram a mesma pessoa e enfrentaram diversas intempéries para chegar a essa conclusão, a esse encontro. Mais uma vez, é o contexto da publicação, aliado com o silêncio fundante que gera essa interpretação. Nesse caso, temos uma interpretação gerada pela força e pelos elementos da própria linguagem das histórias em quadrinhos.

A história de Aline Zouvi mostra uma palestra em tradução simultânea, em que a palestrante e a tradutora acabam falando a mesma linguagem, sempre representada por sinais e não por palavras. Ao final, os sinais da palestra e da tradução se entrecruzam, fazendo uma alusão à relação sexual entre duas mulheres. Nessa história em quadrinhos, é a linguagem pictórica dentro dos balões que faz alusão a dois idiomas diferentes, que move os sentidos do enredo. É também 
a junção de símbolos triangulares que leva o leitor a depreender que as duas mulheres chegaram a um entendimento muito maior do que apenas uma tradução simultânea de idiomas, mas uma tradução de sentimentos e desejos. Temos aqui uma dinâmica que se serve tanto no âmbito cultural como no linguístico.
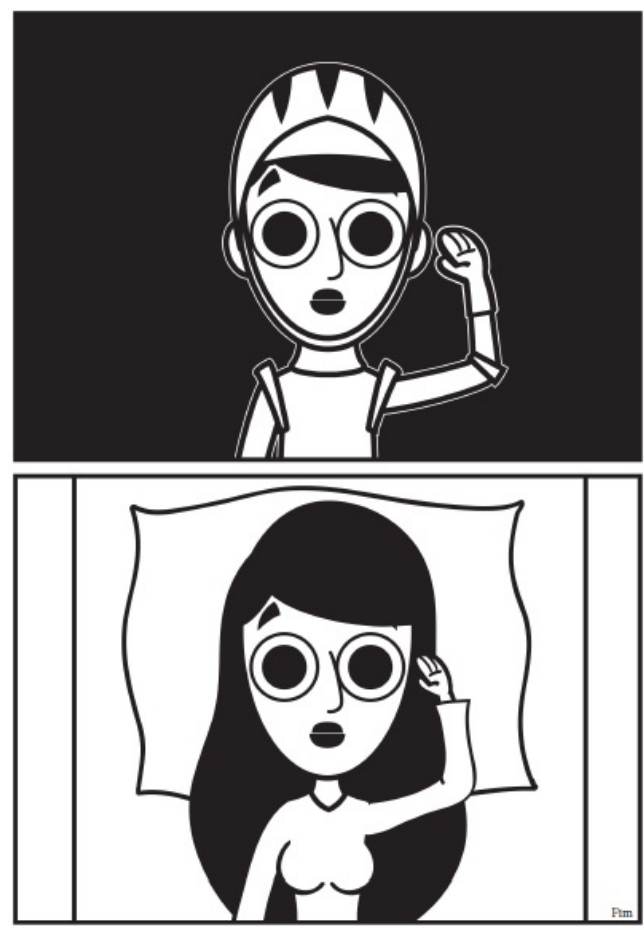

Figura 2: Excerto do quadrinho sem título, de Alice Pereira Fonte: Borges, Irineu, Smee (2021, p. 36).

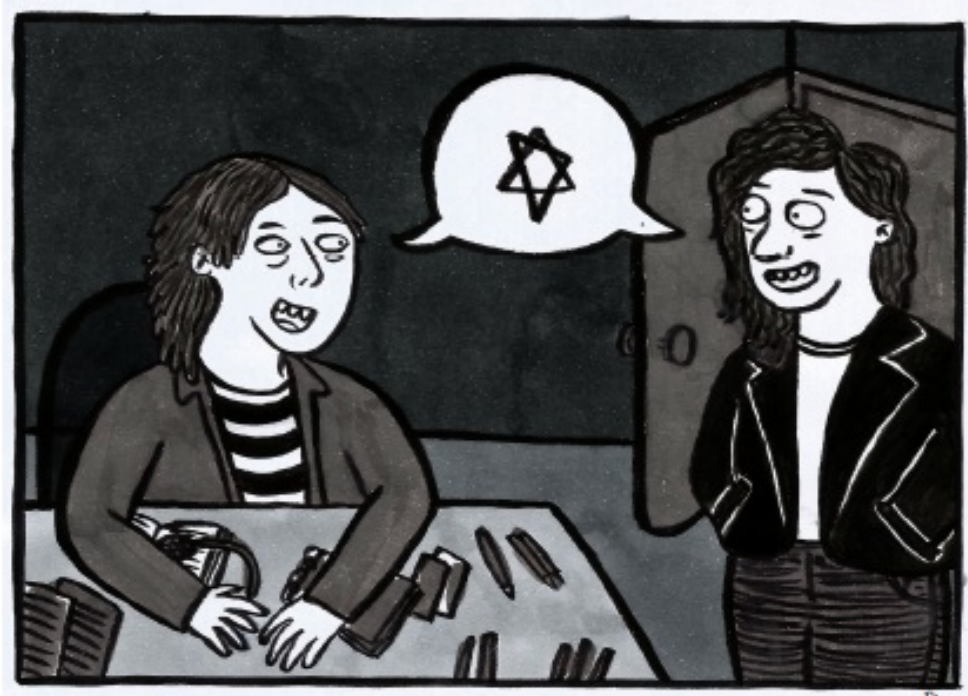

Figura 3: Excerto do quadrinho "Tradução simultânea", de Aline Zouvi Fonte: Borges, Irineu, Smee (2021, p. 68). 
Caio Yo apresenta uma narrativa em que dois garotos se conhecem através de um aplicativo de relacionamento e, posteriormente, se encontram, revelando a fluidez, o imediatismo e o silêncio vocal entre os relacionamentos contemporâneos mediados por aplicativos de mensagens instantâneas. Já a HQ Fada sápica, de Camila Abdanov, representa a busca de uma menina por uma moeda perdida. Com a ajuda da fada, ela acaba encontrando essa moeda e assim pode se encontrar com sua amiga/amada.

Por sua vez, Dani Franck, em seu trabalho para Quadrinhos Queer, faz uma panorâmica pelo espaço de uma casa e mostra como aquele lugar mudou a partir da construção do relacionamento entre duas mulheres. Uma aplicação da memória espacial e visual, bem como das diferenças que unem aqueles que se amam. Nessas três histórias em quadrinhos, o silêncio fundante tem a função de, através da reflexão proporcionada pela arte e pela memória, romper sutilmente o silenciamento das pessoas queer, costumeiramente feito de maneira fulminante e estrondosa, desenvolvendo se não uma violência física, uma violência simbólica que pode deixar feridas psíquicas por toda uma existência queer.

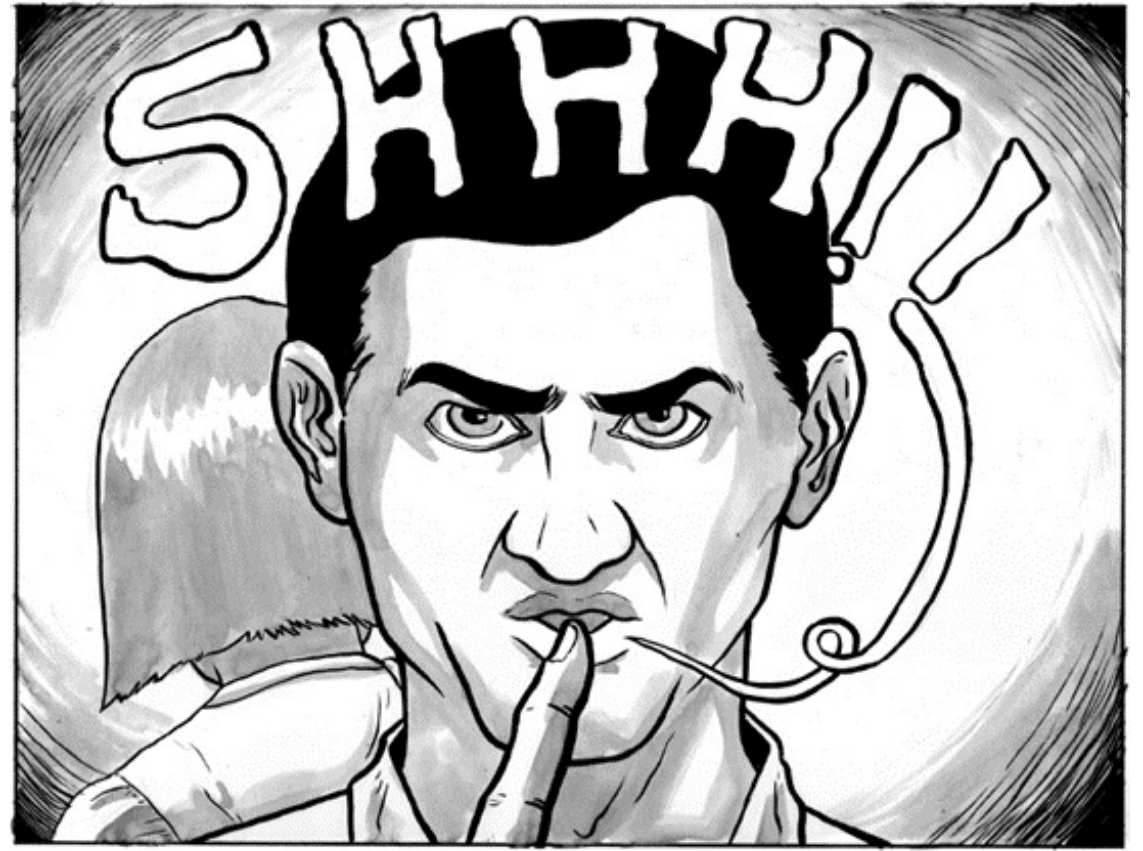

Figura 4: Excerto do quadrinho "Fruto proibido", de Mário César Oliveira Fonte: Borges, Irineu, Smee (2021, p. 234). 
No trabalho de Mário César Oliveira para a coletânea Quadrinhos Queer, temos dois homens em um banheiro público fazendo sexo oral. Após os dois saírem de lá, o leitor descobre que um deles é casado e tem a mulher grávida. Este, então, pede silêncio para que o outro nada fale sobre sua relação sexual no banheiro. A sequência de páginas que vem depois mostra as diferenças entre as formas de encarar o desejo sexual queer. Um deles, "no armário", com medo de se revelar e o outro vivendo tranquilamente sua vida como gay assumido. Temos, transcorrendo durante essas cenas, a letra da música "O que será?", de Chico Buarque.

Durante uma visita ao médico, um homem fica excitado. Depois de ser examinado, revelando seu órgão sexual ereto, o homem recebe sexo oral do médico. Os dois acabam sendo surpreendidos pela secretária do consultório. Esse é o enredo do quadrinho de Rafael Bastos Reis.
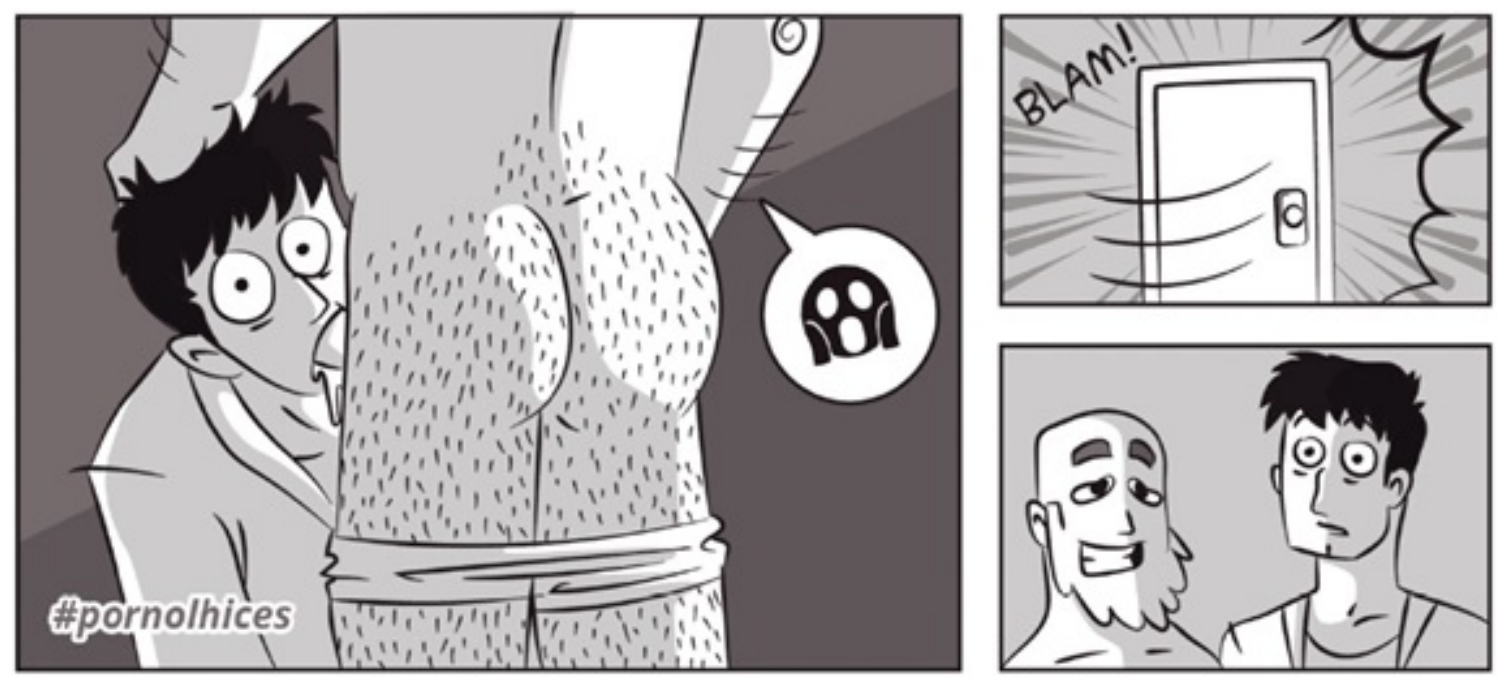

Figura 5: Excerto do quadrinho "Visita ao médico", de Rafael Bastos Reis Fonte: Borges, Irineu, Smee (2021, p. 252).

Até então tivemos, nas histórias em quadrinhos analisadas, formas sutis de romper o silenciamento, demonstrado através de gestos singelos e inseridos na linguagem própria das histórias em quadrinhos. Contudo, nas histórias de Mário e Rafael, temos maneiras mais desafiadoras e contestadoras do silenciamento, que se aproximam do que a teoria queer prega, ou seja, a assimilação de elementos 
tradicionais que são deglutidos em formas de aviltamento e choque para causar uma reação de rompimento no leitor. Geralmente feita através do "desbunde", forma de deixar bastante explícito esse choque e distanciamento das tradições, vemos que o silêncio fundante também é bastante eficaz nesse sentido, podendo, algumas vezes, aproximar-se do silenciamento pela paralisia e estertor que determinadas cenas podem provocar em um leitor mais conservador.

Por outro lado, narrativas mais sutis que trabalham com gestos e aforismos são potentes da mesma forma, pois geram a inquietação interpretativa do movimento dos sentidos que o silêncio causa, como exposto nas seções anteriores. O interessante é que são as "marcas do silêncio", seus rastros e pequenos detalhes que revelam o queer nas histórias em quadrinhos analisadas. Em um trabalho anterior de Miorando (2020), percebemos que nas histórias em quadrinhos é mais difícil perceber e entender alguém como queer. Não temos a dimensão acústica que nos faz perceber o tom da voz e nem conseguimos depreender gestos que poderiam denunciar uma sexualidade que se deseja omitir. Precisamos contar apenas com pequenas pistas conceituais que, como aquelas analisadas nos trabalhos acima, fazem com tenhamos uma ideia de que estamos lidando com personagens e histórias de vida queer.

A identidade queer é revelada através dos gestos nesses quadrinhos silenciosos, sejam gestos escancarados daquilo que o senso comum julgaria por uma identidade e uma sexualidade queer, ou gestos mais sutis, denotando um sentido mais aberto para conotações de carinho ou afeto. A memória cultural brasileira, por exemplo, aceita como normatizante duas mulheres andarem de mãos dadas, mas condena o mesmo ato entre homens. O interessante é que apesar de o silenciamento estar incrustado nas narrativas silenciosas e servir como força motriz para elas, somente em uma delas, a de Mário César Oliveira, é que ele é apresentado de forma explícita. Nas demais histórias, o silenciamento é simbólico, mas ainda assim uma violência contra essas vidas precárias e existências mínimas.

O ato dos personagens de se revelarem queer acaba rompendo não apenas o silenciamento, mas o senso comum. Os autores, nas oito histórias em quadrinhos 
analisadas, acabam criando um subtexto para o leitor e também um momento de reflexão provocado, dessa vez, pelo silêncio fundante. Também não é de se estranhar que alguns autores tenham escolhido o momento de revelação da identidade e/ou da sexualidade queer como forma de encerrar suas histórias. O final da história também é um momento de reflexão que se utiliza do silêncio fundante, o não haver mais história para buscar um entendimento, um novo sentido na mente do leitor.

\section{Considerações finais}

Este artigo buscou entender como ocorre a produção de sentidos de identidades e sexualidades queer em histórias em quadrinhos com temática queer, presentes na obra Quadrinhos Queer. Para isso, apresentamos algumas diferenciações e relações entre silêncio fundante e silenciamento que possuem relação com a produção de sentido e da memória social e coletiva. Esses dois elementos encontram reverberações quando colocamos em oposição memória e silenciamento, pois este último nega o acesso à memória àqueles coletivos que são considerados irreais ou virtuais, que constituem vidas precárias e existências mínimas.

Segundo alguns autores mencionados no decorrer deste artigo, uma das formas de romper o silenciamento pode ser realizada através da arte, que, assim como a memória, tem como uma importante função recriar e ressignificar momentos traumáticos e dar voz às vidas que ficam à margem da sociedade. Nesse sentido, trabalhos como Quadrinhos Queer apresentam representações e representatividades de pessoas queer que rompem com o senso comum. Esse esforço representativo desmistifica ideias preconceituosas sobre o que é ser queer e forja novas identidades através da arte e da mídia quadrinhos, desenvolvendo novas memórias sobre o significado da queerness na sociedade.

Percebemos então como o silenciamento e o apagamento das memórias ou a falta de acesso, manutenção e projeção - das memórias queer causa prejuízos à sua representação e representatividade nas mídias. Muitos apelam para o escracho e para os estereótipos quando se precisa retratar pessoas queer em mídias estáticas e, num sentido amplo, sem som, silenciosas, como os quadrinhos, 
que dependem do texto para determinados entendimentos. Produzir materiais escrachados e estereotipados a respeito de pessoas queer, na atual conjuntura, somente demonstra a limitação de determinados produtores, seja para mídias marginais como os quadrinhos ou para mídias consumidas por todos, como o audiovisual. As histórias em quadrinhos apresentadas em Quadrinhos Queer são exemplos de que a representação queer vai além do humor ou da sexualidade. Também demonstram que o silenciamento sobre as realidades queer, essas existências mínimas ou vidas precárias, pode ser rompido através do bom uso da linguagem e dos processos midiáticos em que estão inseridos, seja utilizando palavras e diálogos ou a singeleza do nada dizer, apenas demonstrar.

\section{Referências}

AHMED, M. CRUCIFIX, B. Comics memory: archives and styles. Nova Iorque: Palgrave Macmillan, 2018.

ASSMANN, A. Espaços de recordação: formas e transformações da memória social. Campinas: Editora Unicamp, 2011.

BORGES, G; IRINEU, E; SMEE, G. (org.) Quadrinhos queer. São José: Skript, 2021.

BUTLER, J. Excitable speech: a politics of the performative. Londres: Routledge, 1997.

BUTLER, J. Problemas de gênero: feminismo e subversão da identidade. 13. ed. Rio de Janeiro: Civilização Brasileira, 2017.

BUTLER, J. Corpos em aliança e a política das ruas: notas para uma teoria performática de assembleia. Rio de Janeiro: Civilização Brasileira, 2018. 
BUTLER, J. Vida precária: os poderes do luto e da violência. Belo Horizonte: Autêntica, 2019.

CANDAU, J. Memória e identidade. São Paulo: Contexto, 2001.

CVETKOVICH, A. Drawing the archive in Alison Bechdel's "Fun home". WSQ: Women's Studies Quarterly, Nova Iorque, v. 36, n. 1-2, p. 111-128, 2008.

GROENSTEEN, T. Comics and narration. Jackson: University Press of Mississippi, 2013.

GROENSTEEN, T. O sistema dos quadrinhos. Nova Iguaçu: Marsupial, 2015.

HALBWACHS, M. A memória coletiva. São Paulo: Editora Revista dos Tribunais, 1990.

LAPOUJADE, D. As existências mínimas. São Paulo: N-1 Edições, 2017.

MARCONDES, C. I. Arzach e o despontar da narrativa gráfica silenciosa. Esferas, Brasília, DF, ano 5, n. 9, p. 153-168, 2016.

MIORANDO, G. S. Memória e quadrinhos: algumas aproximações. Memorare, Tubarão, v. 6, n. 2, p. 37-52, 2019.

MIORANDO, G. S. Os limites do ato performativo na representação queer nos quadrinhos. In: MIORANDO, G. S. Sexo e gênero nos quadrinhos. Leopoldina: ASPAS, 2020. p. 90-125.

ORLANDI, E. P. As formas do silêncio: no movimento dos sentidos. Campinas: Editora Unicamp, 2007. 
POLLACK, M. Memória, esquecimento, silêncio. Estudos Históricos, Rio de Janeiro, v. 2, n. 3, p. 3-15, 1989.

ROHY, V. In the queer archive: Fun home. GLQ: A Journal of Lesbian and Gay Studies, Durham, NC, v. 16, n. 3, p. 341-361, 2010.

VIANA, N. Análise pictórica, modos de ver e modos de retratar. In: REBLIN, I. A. ; NOGUEIRA, N. A. S. Arte sequencial e suas sarjetas metodológicas. Leopoldina: ASPAS, 2018.

submetido em: 5 abr. 2021 | aprovado em: 30 abr. 2021 